\title{
A rare case of intraoral lipoma in a six year-old child: a case report
}

\author{
Meduri Venkateswarlu, Paramkusam Geetha, Mandadi Srikanth* \\ Department of Oral Medicine and Radiology, Kamineti Institute of Dental Sciences, Narketpally, Andhra Pradesh \\ 508254 , India
}

One type of soft tissue lesions of the oral cavity is lipoma, which is a kind of benign tumor composed of mature lipid cells. Although the lipoma presents as one of the most common mesenchymal neoplasms, most tend to develop on the trunk and proximal portions of the extremities. However, lipomas in the oral and maxillofacial region are much less frequent. Here we present a case of an intraoral lipoma in a six year-old child.

Keywords: lipoma; mature fat cells; fibrolipoma

International Journal of Oral Science (2011) 3: 43-46. doi: 10.4248/IJOS11008

\section{Introduction}

The various types of oral peripheral mesenchymal tumors are classified here as Furlong et al. [1]:

- Lipomas

- Myomas (rhabdomyomas and leiomyoma)

- Peripheral nerve tumors (neurofibroma, plexiform type of neurofibroma, schwannoma, traumatic neuroma)

By contrast, the morphologically intraoral lipomas can be classified as Rajendran et al. [2]:

- Diffuse form affecting the deeper tissues

- Superficial form

- Encapsulated form

The oral lipoma has been reported in individuals from 6 weeks of age to 75 years; with the average age being in the early 1950's and with gender distribution appearing to be approximately equal. The buccal mucosa and mucobucal fold are the most common sites; followed by the tongue, floor of the mouth, and lip. In another report, the lip was the second most common site. Less common or even rare locations, have been reported as being the

*Correspondence: Srikanth Dakshina Murthy Mandadi

Tel: 9849207997

E-mail: drsrikanthmd@rediffmail.com

Received 26 March 2010; Accepted 22 June 2010 tongue, soft palate, alveolar ridge, and mental region. Because pain is not a symptom, patients may not be aware of the lesions; but those who are aware report a slow-growing mass that may have been present from 1 month to 30 years [3].

The lipoma usually occurs as a solitary lesion that may be sessile, pedunculated or submerged. It ranges in size from a small lesion approximately $1 \mathrm{~cm}$ in diameter to a massive tumor $5 \mathrm{~cm} \times 3 \mathrm{~cm} \times 2 \mathrm{~cm}$ in dimension. Deeper lesions vary in contour and shape ranging from a well-defined, round contoured swelling to a large, illdefined, lobulated mass. The color, often yellow in tone, depends on the thickness of the overlying mucosa. The surface is typically smooth and non-ulcerated except when traumatized [3].

\section{Case Report}

A male patient, aged six years (Figure 1), came to the Department of Oral Medicine and Radiology with his mother, who claimed he was not able to close his mouth for the past week.

History revealed that the patient had fallen from a bicycle one week prior, but did not present with any oral injuries. The mother then noticed her son's inability to close his mouth. She immediately accessed a local doctor 
44

for an assessment. Removed of the bicycle incident, no other history was found to be significant.

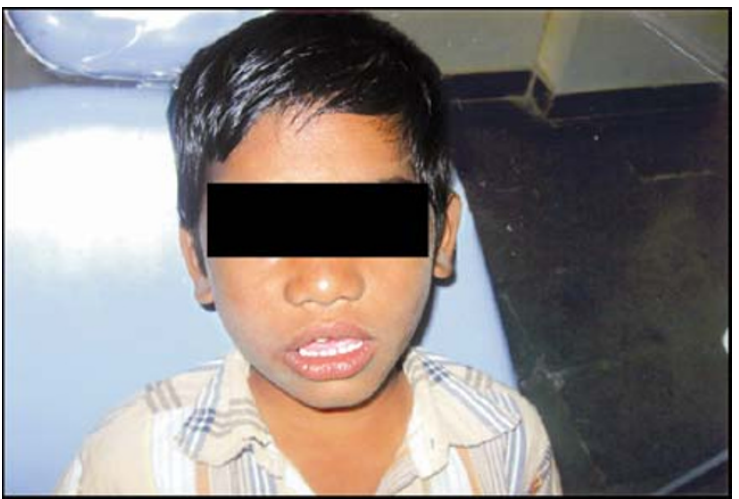

Figure 1 Extraoral view of the patient

An extraoral examination revealed no specific abnormality. An intraoral examination, however, revealed a well-defined, pedunculated growth of normal mucosal color in the right buccal mucosal region, extending from the distal aspect of 85 to the retro-molar region on that side. The surface of the growth was of a faint yellow color, while the periphery region bore teeth indentations. In palpation, the growth was non-tender and firm in consistency. It measured $3 \mathrm{~cm} \times 1.5 \mathrm{~cm}$ in size, with no visible fluctuations of pseudo-membranous slough appearing on its periphery (Figure 2).

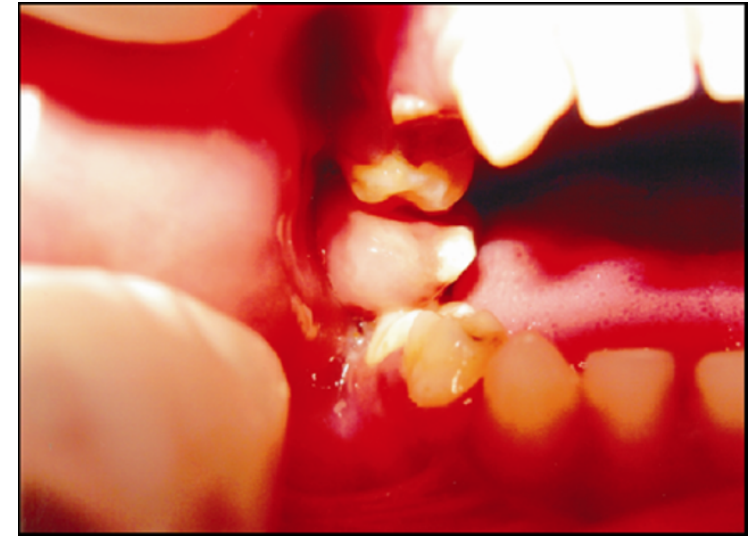

Figure 2 Intra oral photograph of growth

In keeping with the above findings, a provisional diagnosis of irritational fibroma was made, while pyogenic granuloma, peripheral giant cell granuloma, and granular cell myoblastoma were considered as differential diagnoses. Routine blood and radiological tests were performed, but failed to reveal any significant findings and confirmed that blood parameters were within normal limits.
Surgical excision is the current treatment for oral lipomas. The surgical approach is dependent on the site of the tumor and the desired cosmetic result. This patient's lipoma was approached intraorally and, due to its small size, a complete excision was made. No postoperative complications resulted from the procedure.

The histopathology has revealed, however, multiple tissue fragments exhibiting an ulcerated surface with underlying edematous vascularized stroma, intermingled with mature adipose tissue. When stroma is infiltrated with acute and chronic inflammatory cells, as evidenced in this case, the histopathological diagnosis is lipoma (Figure 3). A final diagnosis of intraoral lipoma was, therefore, considered.

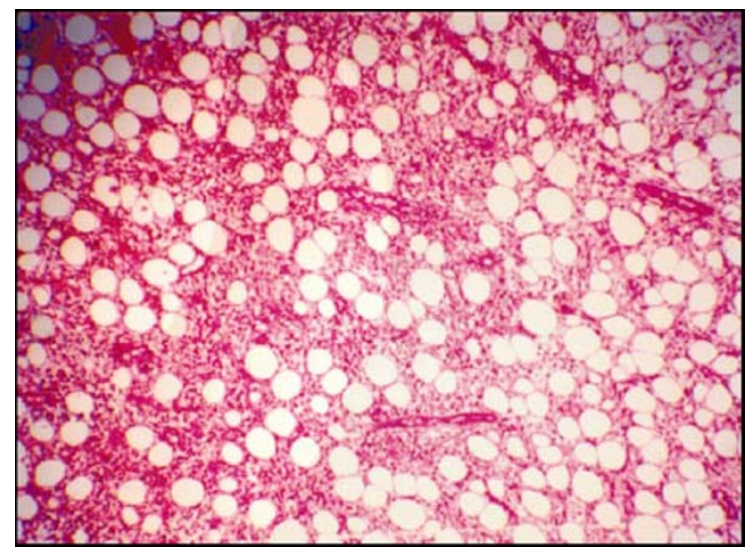

Figure 3 Histopathology of specimen showing mature fat cells

\section{Discussion}

The first description of an oral lesion was provided by Roux in 1848. In his review of alveolar masses, Roux referred to the oral lesion as a "yellow epulis" [2]. Oral lipomas are usually soft, smooth-surfaced nodular masses that can be sessile or pedunculated. Typically the tumor is asymptomatic, and of a subtle or more obvious yellow hue. Oral lipomas more deeply rooted in the tissue may appear pink.

Accounting for fifty percent of all cases, the buccal mucosa and buccal vestibule are the most common intraoral sites. Oral lipomas located on the buccal mucosa may not represent true tumors, but rather herniation of the buccal fat pad through the buccinator muscle. Such cases may occur subsequent to local trauma in young children or the surgical removal of third molars in older patients. Less common sites include the tongue, floor of the mouth, and lips [4].

The lesion is usually non-tender, soft, and almost 
"cheesy" in consistency, but may be fluctuant. It is typically superficial in depth; but may infiltrate the muscle, become fixed to the surrounding tissue, and, therefore, unmovable. Deeply occurring lesions may produce only a slight surface elevation and may be well encapsulated, more diffuse, and less delineated than the superficial variety. This more diffuse form generates the clinical impression of a fluctuant tumor [3].

Most oral lipomas are composed of mature fat cells that differ little in microscopic appearance from the normal fat cells that surround the tumor [4-5]. The tumor is usually well circumscribed and may appear as a thin fibrous capsule. A distinct lobular arrangement of the cells is also often seen.

Few lipomas show rearrangements of $12 \mathrm{q}, 13 \mathrm{q}$, and $6 \mathrm{p}$ chromosomes [2].

The most common microscopic variant of oral lipomas is the fibrolipoma characterized by a significant fibrous component intermixed with lobules of fat cells. The other variants are $[2,4]$ :

- Angiolipoma - a mixture of mature fat cells and numerous small blood vessels.

- Spindle cell lipoma - variable amounts of uniform appearing spindle cells, typically in conjunction with a lipomatous component (i.e. when appearing with a mucoid component, however, the impression of a myxoid lipoma is made).

- Pleomorphic lipoma - presence of spindle cells with bizarre, hyperchromatic giant cells.

- Intramuscular (infiltrating) lipoma - is more deeply situated and has an infiltrative growth pattern that extends between skeletal muscle bundles. When the spindle cells are of smooth muscle origin, the term "myolipoma" may be used, or "angiomyolipoma" when the smooth muscle appears to be derived from the walls of arterioles.

On rare occasions, isolated ductal or tubular adnexal structures are scattered throughout the fat lobules, in which case the term "adenolipoma" is applied. Perineural lipoma has also been reported. Rarely, chondroid or osseous metaplasia may be seen in a lipoma (i.e. osteolipoma, ossifying lipoma, chondroid lipoma, or ossifying chondromyxoid lipoma). Also rare have been reports of hibernoma (i.e. a benign neoplasm of brown fat) occuring in the oral/pharyngeal region.

The above-noted combinations of histological features are of no prognostic significance; although the clinical appearance of color and tissue consistency may vary in accordance with such combinations [3].

Moreover, the cells of oral lipomas appear to differ metabolically from normal fat cells despite being histologically similar. Therefore, a person subjected to a starvation diet will lose fat from normal fat deposits in the body, but not from the lipoma. Furthermore, when lipoprotein lipase activity is reduced, fatty acid precursors are incorporated into lipoma fat at a more rapid rate than into normal fat [2].

In some cases, lipomas of the buccal mucosal region cannot be distinguished from a herniated buccal fat pad without a history of sudden onset post-trauma being nonevident. Lipomas of the oral and pharyngeal regions are, otherwise, simple to differentiate from other lesions; although spindle cell and pleomorphic types must be distinguished from liposarcoma. When metaplastic calcified tissue is present, the lesion may be confused with soft tissue chondroma or osteoma. Multiple head and neck lipomas have been observed in neurofibromatosis, Gardner's Syndrome, encephalocranio cutaneous lipomatosis, multiple familial lipomatosis, and proteus syndrome [2].

Lipoblastomatosis, a rarely-related lesion, is not a true neoplasm but rather a continuation of the normal process of fetal fat development carried on into postnatal life. It is clinically characterized in infants by the occurrence of solitary or multiple soft tissue masses developing at various sites, such as the buttock, chest, axilla or neck [6].

Conservative surgical removal is the choice of treatment for oral lipoma, with occasional recurrences expected. An infiltrating lipoma must often be "debulked", meaning a portion of the infiltrating fat is deliberately left untouched in order to preserve as much normal tissue as possible. Finally, while intramuscular lipomas have a higher recurrence rate because of their infiltrative growth pattern [3], malignant transformations or recurrences in the oral and maxillofacial regions are rare [7].

\section{Conclusion}

Presented in this report is a case of intraoral lipoma in a six year-old child. In referencing the literature to date, this type of case has been rarely documented.

\section{References}

1 Furlong MA, Fanburg-Smith JC, Childers EL. Lipoma of the oral and maxillofacial region: site and subclassification of 125 cases. Oral Surg Oral Med Oral Pathol Oral Radiol Endod 2004; 98: 441-450.

2 Rajendran R, Sivapathasundharam B. Shafer's textbook of oral pathology. 6th Edition. India: Elsevier, 2009.

3 Wood NK, Goaz PW. Differential diagnosis of oral and maxillofacial regions. 5th Edition. St Louis: Mosby, 1997. 
4 Neville BW, Damm DD, Allen CM, Bouquot JE. Oral and maxillofacial pathology. 3rd Edition. Philadelphia: Saunders, 2009.

5 Greenberg MS, Glick M, Jonathan AS. Burket's oral medicine. 11th Edition. India: BC Decker, 2008.

6 Darling MR, Daley TD. Intraoral chondroid lipoma: a case report and immunohistochemical investigation. Oral Surg Oral Med Oral Pathol Oral Radiol Endod 2005; 99: 331333.

7 Adoga AA, Nimkur TL, Manasseh AN, Echejoh GO. Buccal soft tissue lipoma in an adult Nigerian: a case report and literature review. J Med Case Reports 2008; 2: 382. 